\title{
Risk factors associated with venous thromboembolism in patients undergoing spine surgery
}

\author{
Keaton Piper, BSc, Hanna Algattas, MD, Ian A. DeAndrea-Lazarus, BA, \\ Kristopher T. Kimmell, MD, Yan Michael Li, MD, PhD, Kevin A. Walter, MD, \\ Howard J. Silberstein, MD, and G. Edward Vates, MD, PhD \\ Department of Neurosurgery, University of Rochester Medical Center, Rochester, New York
}

OBJECTIVE Patients undergoing spinal surgery are at risk for developing venous thromboembolism (VTE). The au-
thors sought to identify risk factors for VTE in these patients. METHODS The American College of Surgeons National Surgical Quality Improvement Project database for the years 2006-2010 was reviewed for patients who had undergone spinal surgery according to their primary Current Procedural Terminology code(s). Clinical factors were analyzed to identify associations with VTE.

RESULTS Patients who underwent spinal surgery $(n=22,434)$ were identified. The rate of VTE in the cohort was $1.1 \%$ (pulmonary embolism $0.4 \%$; deep vein thrombosis $0.8 \%$ ). Multivariate binary logistic regression analysis revealed 13 factors associated with VTE. Preoperative factors included dependent functional status, paraplegia, quadriplegia, disseminated cancer, inpatient status, hypertension, history of transient ischemic attack, sepsis, and African American race. Operative factors included surgery duration $>4$ hours, emergency presentation, and American Society of Anesthesiologists Class III-V, whereas postoperative sepsis was the only significant postoperative factor. A risk score was developed based on the number of factors present in each patient. Patients with a score of $\geq 7$ had a 100 -fold increased risk of developing VTE over patients with a score of 0 . The receiver-operating-characteristic curve of the risk score generated an area under the curve of $0.756(95 \% \mathrm{Cl} 0.726-0.787)$.

CONCLUSIONS A risk score based on race, preoperative comorbidities, and operative characteristics of patients undergoing spinal surgery predicts the postoperative VTE rate. Many of these risks can be identified before surgery. Future protocols should focus on VTE prevention in patients who are predisposed to it.

http://thejns.org/doi/abs/10.3171/2016.6.SPINE1656

KEY WORDS venous thromboembolism; spine surgery; ACS NSQIP; quality; risk score

$\mathrm{D}$ ESPITE more than a century of incremental progress in decreasing patient morbidity and death, the rates of certain surgical complications remain high in specific patient populations. ${ }^{2,16,21}$ In addition to harming the patient, surgical complications add significant financial burden on the health care system. ${ }^{33}$ One prospective observational study that analyzed spine surgery outcomes revealed that even minor complications increased costs by more than $\$ 8000$ per patient, on average. ${ }^{46}$ Perioperative care improvement offers substantial potential for reducing health care costs and preventing surgical complications. In 2006, the Centers for Medicare and Medicaid, in con- junction with organizations such as the Joint Commission and the Leapfrog Group, implemented the Surgical Care Improvement Project to reduce surgical complication rates. With hospital reimbursement now linked to surgical outcomes, hospitals have developed protocols for tracking and preventing surgical complications. ${ }^{23}$ One core goal of the Surgical Care Improvement Project is to combat the development of venous thromboembolism (VTE), including pulmonary embolism (PE) and deep venous thromboembolism (DVT). Although effective VTE chemoprophylaxis exists, the decision to medicate is complicated by the associated increased risk of hemorrhage. ${ }^{5}$ To cre-

ABBREVIATIONS ACS = American College of Surgeons; $\mathrm{ASA}=$ American Society of Anesthesiologists; $\mathrm{AUC}=$ area under the curve; $\mathrm{BMI}=$ body mass index; $\mathrm{CPT}=\mathrm{Cur}-$ rent Procedural Terminology; DVT = deep venous thromboembolism; NSQIP = National Surgical Quality Improvement Project; PE = pulmonary embolism; SCR = surgical clinician reviewer; VTE $=$ venous thromboembolism.

SUBMITTED January 10, 2016. ACCEPTED June 20, 2016.

INCLUDE WHEN CITING Published online September 2, 2016; DOI: 10.3171/2016.6.SPINE1656. 
ate an evidence-based approach to VTE prophylaxis, the risk factors that predispose patients to the development of VTE need to be explored further for each type of surgery.

When planning neurosurgical procedures, knowing a patient's VTE risk is of particular importance, because chemoprophylaxis has been associated with intracranial hemorrhage and epidural hematoma, both of which can produce irreversible, devastating neurological deficits. ${ }^{1,4,7,14}$ Recent studies have shown that clinicians more commonly avoid pharmacological prophylaxis out of fear of hemorrhage; yet, PEs have been shown to result in a mortality rate higher than that of hemorrhages in patients undergoing neurosurgery. ${ }^{29,30,35}$ With this cautious avoidance of iatrogenic hemorrhage, patients can be harmed by preventable PEs.

It is difficult to understand the full magnitude of VTE complications in patients after spine surgery, because studies have revealed various rates for PEs and DVTs (from $0.3 \%$ to $31 \%$ ). ${ }^{11,13,15,25,28,31,36,41}$ Variability in the data stems from limited sample sizes and different inclusion criteria. ${ }^{38}$ The discrepancies in the data suggest that some of the cohorts might have had characteristics that predisposed them to VTE development. There have been several studies aimed at identifying these potential VTE risk factors, but they were also severely restricted by small sample sizes. ${ }^{4,10,31,42}$ The North American Spine Society's recent literature review on antithrombotic therapies for patients undergoing spine surgery stated that there is insufficient evidence in the literature to make recommendations based on the risks or benefits of VTE chemoprophylaxis. ${ }^{4}$

There is currently no gold-standard algorithm for determining a patient's risk of VTE development. ${ }^{6}$ A large cohort analysis aimed at identifying VTE risk factors in patients undergoing spine surgery could clarify current discrepancies in research and help to provide individualized recommendations regarding VTE chemoprophylaxis in patients undergoing spine surgery., 4, To meet this need, large clinical databases have made massive expansions over the past 20 years and can provide extensive details on perioperative characteristics of all surgeries performed in many different hospitals across the United States.

The purpose of this study was to analyze a large database to identify risk factors for VTE in patients undergoing spine surgery. Clinical factors were examined using information found in the American College of Surgeons (ACS) National Surgical Quality Improvement Project (NSQIP) database (see www.facs.org/quality-programs/ acs-nsqip).$^{20}$ The NSQIP database records characteristics, operative factors, and postoperative complications of patients who underwent surgery. For this analysis, data from the years 2006-2010 were selected and examined. Risk factors were identified and used to calculate a risk score that could be used in the future to predict a patient's propensity to develop VTE.

\section{Methods \\ Data Collection}

All patient data used in this analysis came from the ACS-NSQIP data set. The NSQIP is an effort by the ACS aimed at the standardized collection of national surgi- cal data with a goal of improving the quality of health care. The ACS-NSQIP collects its data from a surgical clinician reviewer (SCR) at each associated hospital. The SCR is trained by the ACS-NSQIP organization, is audited regularly, and maintains a degree of separation from the facilities' surgeons. ${ }^{18}$ The SCR at each facility records and reports preoperative to 30-day-postoperative data on randomly assigned patients directly to the NSQIP. Additional materials describing training and auditing can be found at the ACS-NSQIP website (www.facs.org/ quality-programs/acs-nsqip/program-specifics/data). Between 2006 and 2010, more than 200 hospitals reported to the NSQIP, and those data were analyzed in this study. ${ }^{17,18,22,40}$

\section{Univariate Analysis}

A total of 22,434 adult patients who underwent spinal surgery between 2006 and 2010 were identified via their primary Current Procedural Terminology (CPT) code. Univariate 2-tailed chi-square analysis and the Fischer exact test, where appropriate, were used with nominal and ordinal variables to identify clinical associations with the occurrence of VTE.

The following clinical factors from the ACS-NSQIP data set were analyzed: sex; race; CPT code; inpatient status; transfer status; age; anesthesia used; level of resident supervision; height; weight; body mass index (BMI); history of diabetes; history of smoking; history of alcohol use; history of dyspnea; do-not-resuscitate status; functional status prior to surgery; ventilator-dependent spine surgery; history of esophageal varices; history of congestive heart failure; history of myocardial infarction; history of percutaneous coronary intervention; history of angina; history of hypertension requiring medication; history of peripheral vascular disease; history of limb pain at rest or gangrene; history of renal failure; history of transient ischemic attack or stroke prior to surgery; history of bleeding disorder; history of chemotherapy or radiotherapy; history of systemic sepsis; pneumonia prior to surgery; ascites prior to surgery; on dialysis prior to surgery; impaired sensorium prior to surgery; hemiplegia, paraplegia, or quadriplegia prior to surgery; presence of a tumor involving the CNS; disseminated cancer prior to surgery; open wound or wound infection prior to surgery; steroid use for a chronic disease at the time of spine surgery; greater than $10 \%$ weight loss prior to surgery; disseminated cancer prior to surgery; open wound or wound infection prior to surgery; blood transfusion of more than 4 units during the spine surgery; pregnant at time of surgery; surgery in 30 days prior to the spine surgery; preoperative laboratory values; surgeon who dictated the records; highest level of training of resident; emergency presentation; wound classification; American Society of Anesthesiologists (ASA) ${ }^{8}$ physical status score; airway trauma during spine surgery; number of red blood cell transfusions during spine surgery; duration of anesthesia; duration of spine surgery and total operating room time; intraoperative complication; and a number of postoperative factors including wound infection, pneumonia, unplanned intubation, $\mathrm{PE}$, prolonged ventilation (greater than 48 hours), renal insufficiency or failure, dehiscence, urinary tract infection, stroke, coma 
TABLE 1. VTE events and 30-day mortality rates

\begin{tabular}{lcc}
\hline \multicolumn{1}{c}{ Event } & Total No. of Patients (\%) & Mortality Rate (\%) \\
\hline No VTE & $22,193(98.9)$ & 0.4 \\
\hline VTE & $241(1.1)$ & 4.1 \\
\hline DVT & $174(0.8)$ & 4.6 \\
\hline PE & $91(0.4)$ & 3.3 \\
\hline Overall cohort & 22,434 & 0.5 \\
\hline
\end{tabular}

lasting longer than 24 hours, cardiac arrest requiring cardiopulmonary resuscitation, myocardial infarction, need for blood transfusions, DVT, sepsis, septic shock, and return to the operating room.

Univariate chi-square analysis was used to identify associations between VTE and clinical factors. The threshold for significance was set using an adjusted $\alpha$ value as determined by Holm-Bonferroni correction. Odds ratios were computed when appropriate. Based on univariate analysis, some categorical variables were converted to binary variables (functional status dependent $=1$; ASA Score III-V $=1$; age $>60$ years $=1$; operating room time $>4$ hours $=1$; $\mathrm{BMI}>30=1$ ). Binary variables were generated for these categories to calculate ORs and improve the multivariate regression model.

\section{Computation of VTE Risk Score}

We used multivariate binary logistical regression (entry level 0.05 , exit level 0.1 ) to analyze the clinical factors with a $p$ value of $\leq 0.05$ to determine variables independently associated with VTE events. Preoperative and intraoperative variables were controlled when postoperative complications associated with VTE were independently subjected to multivariate logistic regression. This analysis excluded postoperative events in which the VTE occurred before the complication of interest. Covariate interactions were identified also with chi-square analysis, and these interactions were incorporated stepwise in iterations of multivariate regression; covariate interactions ultimately did not affect the validity of the multivariate model. Analysis of the interactions between postoperative covariates yielded predictably significant interactions between postoperative complications but, similarly, did not affect the multivariate model. Goodness of fit of the multivariate regression model was assessed using the Hosmer-Lemeshow test; $p$ $>0.05$ indicates a model that fits the data appropriately.

A total of 13 factors were identified as significant after multivariate regression and were included in the creation of a risk score. Each factor was converted to a binary variable so that the presence of each given factor was assigned a score of 1. Each independent risk factor was assigned 1 point. The factors were used collectively to calculate a patient's VTE risk score. Patients were assigned a total score for VTE risk, and scores ranged from 0 to 13 (median score 2). Because of the small number of patients with a score that exceeded 7, scores above that threshold were grouped together. All patient VTE risk scores were entered into a receiver-operating-characteristic curve, which yielded an area-under-the-curve (AUC) value to grade the predictability of the model; AUC values greater than 0.700
TABLE 2. Factors associated with VTE incidence after univariate and multivariate analysis*

\begin{tabular}{lc}
\hline \multicolumn{1}{c}{ Factor } & OR $(95 \% \mathrm{Cl})$ \\
\hline Operation time $\geq 4$ hours & $3.59(2.77-4.65)$ \\
\hline Dependent functional status & $4.34(3.20-5.89)$ \\
\hline Paraplegia & $3.74(2.69-5.20)$ \\
\hline Emergency presentation & $5.07(3.32-7.75)$ \\
\hline ASA score $\geq I I I$ & $2.73(2.09-3.56)$ \\
\hline Sepsis & $5.47(3.52-8.50)$ \\
\hline Disseminated cancer & $6.83(4.10-11.36)$ \\
\hline Inpatient status & $7.13(3.17-16.05)$ \\
\hline Hypertension & $2.08(1.59-2.72)$ \\
\hline Quadriplegia & $5.63(3.02-10.48)$ \\
\hline History of ischemic attack & $2.95(1.70-5.10)$ \\
\hline Postoperative sepsis & $5.15(2.69-9.86)$ \\
\hline African American race & $2.11(1.46-3.06)$ \\
\hline
\end{tabular}

* All categories had a $p$ value of $<0.001$.

represent acceptable discrimination. ${ }^{19}$ SPSS 18.0 software (IBM) was used for all statistical analyses.

\section{Results}

The rate of VTE in this cohort was $1.1 \%$; specifically, $0.4 \%$ were PE, and $0.8 \%$ were DVT. Of the 241 patients in this cohort with VTE, 24 (10\%) suffered from both PE and DVT. Both PE and DVT were statistically linked to a nearly 10 -fold increase in the 30 -day mortality rate for both variables (Table 1).

Univariate analysis revealed a number of preoperative, operative, and postoperative characteristics significantly associated with increased risk of developing VTE. Preoperative factors associated with VTE included dependent functional status, paraplegia, quadriplegia, disseminated cancer, inpatient status, hypertension, history of ischemic attack, sepsis, African American race, presence of tumor, diabetes mellitus, dyspnea, and chemotherapy in the previous 30 days. Operative factors associated with VTE included surgery time $\geq 4$ hours, emergent presentation, clean post-spine surgery wound, contaminated post-spine surgery wound, and ASA Score III-V. Postoperative factors associated with the development of VTE included development of infection, bleeding, sepsis, septic shock, urinary tract infection, and ventilator requirement (Tables 2 and 3).

Factors examined by univariate analysis were investigated further with multivariate binary regression analysis, which determined dependent functional status, paraplegia, quadriplegia, disseminated cancer, inpatient status, hypertension, history of ischemic attack, preoperative sepsis, African American race, surgery time $\geq 4$ hours, emergent presentation, ASA Score III-V, and postoperative development of sepsis to be independent statistically significant risk factors (Table 2). The VTE risk score showed high predictability of VTE, with incidence rates of $0.1 \%$ for those with a score of 0 and $11.7 \%$ for those with a score of $\geq 7$, and the distributions for PE and DVT were similar (Fig. 1). A higher VTE risk score also correlated with an 
TABLE 3. Factors associated with VTE incidence after univariate analysis only*

\begin{tabular}{ll}
\hline \multicolumn{1}{c}{ Factor } & OR $(95 \% \mathrm{Cl})$ \\
\hline Postop infection & $3.97(2.61-6.06)$ \\
\hline Postop bleeding & $3.22(2.61-6.06)$ \\
\hline Tumor & $5.07(3.02-8.52)$ \\
\hline Previous op w/in 30 days & $3.36(2.04-5.55)$ \\
\hline Postop septic shock & $9.26(3.97-21.64)$ \\
\hline Contaminated wound & $2.41(1.52-3.83)$ \\
\hline Clean wound & $0.42(0.26-0.66)$ \\
\hline Diabetes mellitus & $1.90(1.34-2.69)$ \\
\hline Need for postop ventilator & $4.79(2.33-9.86)$ \\
\hline Dyspnea & $0.51(0.35-0.76)$ \\
\hline Postop UTI & $3.07(1.71-5.54)$ \\
\hline Chemotherapy & $6.89(2.76-17.25)$ \\
\hline
\end{tabular}

UTI = urinary tract infection.

* All categories had a $p$ value of $\leq 0.001$.

increased mortality rate and increased average length of stay (Table 4). The VTE risk score's ability to predict VTE was assessed by using a receiver-operating-characteristic curve. The AUC was 0.757 (95\% CI 0.727-0.788).

\section{Discussion}

In this analysis, we attempted to identify factors and further stratify patients according to their risk of VTE resulting from spine surgery. By analyzing preoperative characteristics that predispose patients to developing VTE, evidence-based decisions can be made for when to use chemoprophylaxis. In addition, measures can be taken to attenuate these risk factors with the goal of diminishing VTE rates and associated health care costs in patients undergoing spine surgery.

The rise in administrative databases and clinical registries offers an avenue through which the previous limitations of small sample sizes and difficulties associated with performing randomized controlled trials can be overcome.
The ACS-NSQIP database was designed by clinicians and offers the advantage of detailed clinically pertinent factors that contribute to surgical outcomes and complications. The NSQIP database has been shown by several studies to improve surgical quality at local levels. ${ }^{17,18}$

The NSQIP database has been used to examine risk factors that affect VTE rates with general surgery, ${ }^{32,45}$ breast surgery, ${ }^{43}$ vascular surgery, $, 34,37$ oncological surgery, ${ }^{27}$ urological procedures, ${ }^{44}$ and other neurosurgical procedures..$^{23}$ These published studies helped to design the methods of this study and minimize the confounding variables when comparing VTE rates among surgeries. Comparing our results, particularly the rates of DVT and $\mathrm{PE}$, with those of previous studies is difficult because of the inconsistencies in previous measures of VTE in patients undergoing spine surgery. However, the rates calculated here are in line with the mean VTE rates from larger retrospective analyses (approximately 1\%-3\%). ${ }^{15,38}$ These rates (VTE $1.1 \%$, DVT $0.8 \%$, and PE $0.4 \%$ ) show that spine surgery as a whole does not necessarily result in an increased incidence. This rate might be slightly underestimated, because the NSQIP reports only symptomatic VTEs. The major strengths of the NSQIP registry lie with the extensive associated factors reported for all surgeries that were analyzed here.

When comparing the findings, we identified similar factors contributing to increased VTE risk, including ASA Score $\geq$ III, disseminated cancer, emergency presentation, preoperative sepsis, dependent functional status, and operation time $\geq 4$ hours. Other factors that were significant in other studies and significant here in univariate analysis included the presence of tumor involving the CNS and need for postoperative ventilator for $\geq 48$ hours. Although these factors were significant in univariate analysis, they were not deemed significant in our multivariate analysis. Other factors that have been linked to increased VTE risk with other surgeries but were not significant in this study included increased BMI, steroid use, postoperative pneumonia, and postoperative urinary tract infection. ${ }^{9,23,27,32,34,37,43,45}$ It is interesting to note that a number of factors that were not identified in other NSQIP analyses were identified here to be associated with an increased risk of VTE, including

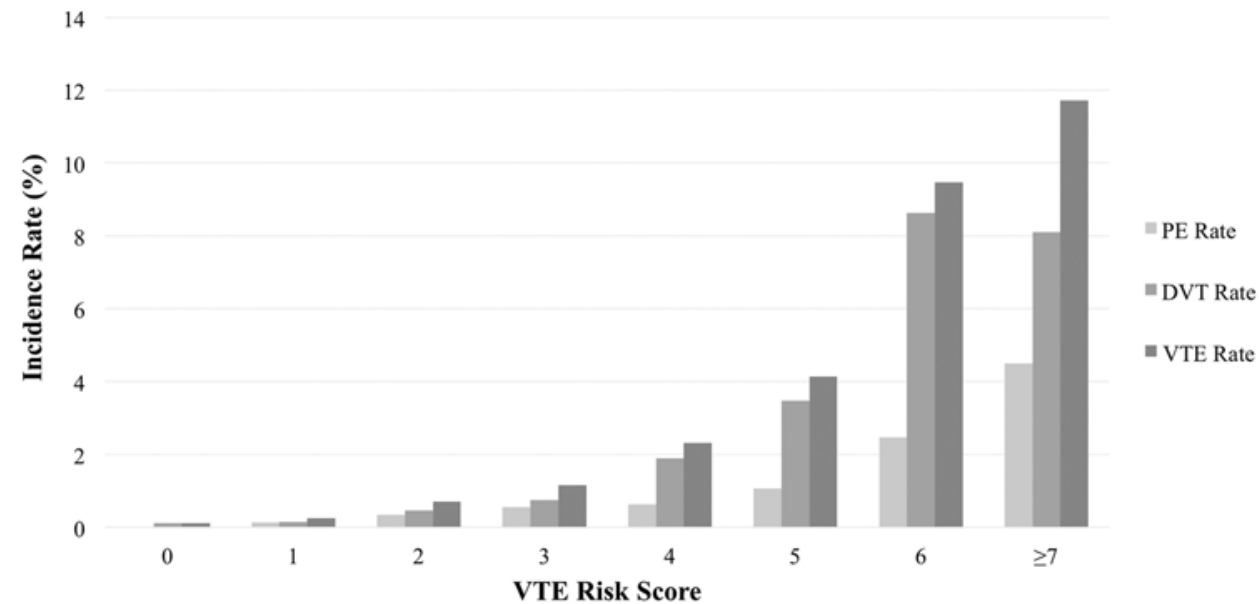

FIG. 1. Rates of PE, DVT, and VTE grouped according to VTE risk score. 
TABLE 4. VTE risk scores and rates

\begin{tabular}{ccccccc}
\hline $\begin{array}{c}\text { VTE } \\
\text { Risk } \\
\text { Score }\end{array}$ & $\begin{array}{c}\text { No. of } \\
\text { Patients } \\
(\% \text { of total) }\end{array}$ & $\begin{array}{c}\text { VTE } \\
\text { Rate } \\
(\%)^{*}\end{array}$ & $\begin{array}{c}\text { RVT } \\
\text { Rate } \\
(\%)^{*}\end{array}$ & $\begin{array}{c}\text { RE } \\
(\%)^{*}\end{array}$ & $\begin{array}{c}\text { Mortality } \\
\text { Rate } \\
(\%)^{*}\end{array}$ & $\begin{array}{c}\text { Average } \\
\text { Hospital } \\
\text { LOS } \\
(\text { days })^{*}\end{array}$ \\
\hline 0 & $1702(7.6)$ & 0.1 & 0.1 & 0.0 & 0.1 & 1 \\
\hline 1 & $6026(26.9)$ & 0.3 & 0.2 & 0.1 & 0.3 & 2 \\
\hline 2 & $6087(27.1)$ & 0.7 & 0.5 & 0.3 & 0.7 & 3 \\
\hline 3 & $5096(22.7)$ & 1.2 & 0.8 & 0.6 & 1.2 & 4 \\
\hline 4 & $2419(10.8)$ & 2.3 & 1.9 & 0.6 & 2.3 & 6 \\
\hline 5 & $750(3.3)$ & 4.1 & 3.5 & 1.1 & 4.1 & 11 \\
\hline 6 & $243(1.1)$ & 9.5 & 8.6 & 2.5 & 9.5 & 14 \\
\hline$\geq 7$ & $111(0.5)$ & 11.7 & 8.1 & 4.5 & 11.7 & 18 \\
\hline
\end{tabular}

paraplegia, quadriplegia, inpatient status, hypertension, history of ischemic attack, and African American race.

Although not identified by NSQIP analyses, these factors have been noted in other studies with different patient settings as potential risks for VTE. 3,12,13,24,26 For instance, Lee et al. ${ }^{24}$ performed a small multivariate analysis that predicted that hypertension is a risk factor for any complication in patients undergoing cervical spine surgery. The results of another study by Bell et al., ${ }^{3}$ who analyzed 2 large cohorts, suggested that African American race is a risk factor for VTE development. Folsom et al. ${ }^{12}$ proposed that the increased rate of VTE development in African American patients might be because they have an increased prevalence of hemoglobin S. As for the VTE risk linked to paraplegia and quadriplegia, we can speculate that the significance is a result of their association with traumatic spine injury that requires surgery and the immobility of these patients. ${ }^{13,26}$ It is important to not classify these as risk factors for VTE development unique to spine surgeries without further investigation of them in other surgical settings.

Although the finding that these clinical factors are associated with VTE is not novel, we believe our development of a risk score demonstrates that these clinical factors are additive in their association with VTE, which is a novel finding. These results raise several questions that merit discussion and future research. Although spine surgery results in a low incidence of VTE development, certain characteristics predispose patients to VTE and can increase their risks nearly 100 -fold. Having simple methods for identifying these factors and thus preventing surgical complications are particularly important now with the shift away from fee-for-service toward quality-based reimbursement models. Most of the factors identified here are patient characteristics that are identifiable before surgery, which is important because surgical management can be adjusted to reduce complications based on the patient's VTE risk. The VTE risk score presented here provides a simple means for clinicians to calculate patient VTE risk at the bedside and can aid in making an evidence-based judgment on when to use chemoprophylaxis.
The VTE risk score shows a clear correlation between increased rate of VTE and each additional VTE risk factor identified here (Table 4). A value of 1 was assigned to each risk factor in hopes of making calculation of the risk score more applicable to clinicians at the bedside with time constraints. The risk-score trend shown in Fig. 1 shows that the nonweighted risk score generated here still predicts VTE development. There is great utility in the simplicity of this calculation for clinical use. Still, further research should be directed toward exploring the pathogenesis and significance of each risk factor. By better understanding each risk factor, a weighted VTE risk-score calculator could be developed to provide a more accurate determination of VTE development based on which unique risk factors each patient has. Of the 13 significant VTE risk factors, only 1 factor was postoperative. With the majority of the factors identifiable before surgery, the VTE risk score shows great promise for preventing VTE development through bedside applications. By studying these 13 VTE risk factors specifically in patients undergoing spine surgery, research efforts can be focused on reducing the development of VTE.

This study has several limitations. Any retrospective analysis has a potential for error due to selection bias; however, the ACS-NSQIP attempted to reduce selection bias by expanding the number of hospitals that participate in the database. Although the breadth of the database has benefits, it also raises concerns regarding the quality and reliability of the data because of potentially different interpretations of the parameters for reportable events. This concern is minimized by the demanding data-quality requirements that have affected the quality of surgical care in other studies. ${ }^{17}$ The NSQIP set the standard for DVT to mean that a clot demands anticoagulation or vena cava filter placement in addition to diagnosis by duplex ultrasound, venography, or computed tomography of a thrombosis occurring along a vein. ${ }^{20}$ As for PE, the NSQIP requires that the diagnosis be made by either a highly probable ventilation-perfusion scan or definitively with another imaging modality. ${ }^{20}$ The strict requirements can still contribute to selection bias, because only hospitals with certain resources, predominantly large academic institutions and research facilities, contribute to the ACSNSQIP data set. Another limitation of the ACS-NSQIP database is that the method of VTE prophylaxis is not reported to the database. Patients with known VTE risk factors might have been offered a prophylactic measure that prevented a VTE, and therefore, important risk factors might not have been fully evident in our study. However, our study still identified 13 risk factors that might be less obvious and still significant, because the lack of reporting VTE prophylaxis is more likely to result in the underestimation of a risk factor than overestimation.

It is obvious that analysis based on a data set is limited by the data collected. A limitation of our study resides in details about each PE and DVT that occurred in these patients, because the ACS-NSQIP data set does not provide information on the location of the VTE. Additional relevant data lacking in the ACS-NSQIP database would be information regarding the use of chemoprophylaxis and resulting hemorrhagic complications. Another limitation 
of our model is that it has not been validated. Future investigations should aim to validate the utility of this VTE risk score in predicting VTE in other neurosurgical cohorts and assessing other factors intrinsic to the surgery, such as surgical approach, that can be added to the score. Validation of this study might be achieved through repeating this risk-factor analysis with data from other national databases and with newer data to compare the significant risk factors. In addition, a prospective study analyzing various VTE-prophylaxis strategies in patients thought to be at high risk for VTE based on the score presented here would be a reasonable next step for further validation.

\section{Conclusions}

Although the rate of VTE incidence in patients undergoing spinal surgery is low, the potential for severe complications from clotting and hemorrhaging that lead to epidural hematoma raises concern for identifying patients at high risk for VTE development. A number of patient and operative characteristics have been linked to increased risk of VTE. The VTE risk score presented here found 13 unique factors that increase a patient's risk of developing a PE or DVT. Additional studies should aim to validate this score and inspect the clinical benefits of VTE prophylaxis in patients at high risk.

\section{References}

1. Agnelli G: Prevention of venous thromboembolism in surgical patients. Circulation 110 (24 Suppl 1):IV4-IV12, 2004

2. Anderson FA Jr, Zayaruzny M, Heit JA, Fidan D, Cohen AT: Estimated annual numbers of US acute-care hospital patients at risk for venous thromboembolism. Am J Hematol 82:777782, 2007

3. Bell EJ, Lutsey PL, Basu S, Cushman M, Heckbert SR, Lloyd-Jones DM, et al: Lifetime risk of venous thromboembolism in two cohort studies. Am J Med 129:339.e19-339. e26, 2016

4. Bono CM, Watters WC III, Heggeness MH, Resnick DK, Shaffer WO, Baisden J, et al: An evidence-based clinical guideline for the use of antithrombotic therapies in spine surgery. Spine J 9:1046-1051, 2009

5. Buesing KL, Mullapudi B, Flowers KA: Deep venous thrombosis and venous thromboembolism prophylaxis. Surg Clin North Am 95:285-300, 2015

6. Camden R, Ludwig S: Prophylaxis against venous thromboembolism in hospitalized medically ill patients: Update and practical approach. Am J Health Syst Pharm 71:909-917, 2014

7. Cote LP, Greenberg S, Caprini JA, Stone J, Arcelus JI, López-Jiménez L, et al: Outcomes in neurosurgical patients who develop venous thromboembolism: a review of the RIETE registry. Clin Appl Thromb Hemost 20:772-778, 2014

8. Davenport DL, Xenos ES: Deep venous thrombosis after repair of nonruptured abdominal aneurysm. J Vasc Surg 57:678-683, 683.e1, 2013

9. Dripps RD: New classification of physical status. Anesthesiology 24:111, 1963

10. Eskildsen SMMS, Moll S, Lim MR: An algorithmic approach to venous thromboembolism prophylaxis in spine surgery. J Spinal Disord Tech 28:275-281, 2015

11. Fang MC, Maselli J, Lurie JD, Lindenauer PK, Pekow PS, Auerbach AD: Use and outcomes of venous thromboembolism prophylaxis after spinal fusion surgery. J Thromb Haemost 9:1318-1325, 2011
12. Folsom AR, Tang W, Roetker NS, Kshirsagar AV, Derebail VK, Lutsey PL, et al: Prospective study of sickle cell trait and venous thromboembolism incidence. J Thromb Haemost 13:2-9, 2015

13. Giorgi Pierfranceschi M, Donadini MP, Dentali F, Ageno W, Marazzi M, Bocchi R, et al: The short- and long-term risk of venous thromboembolism in patients with acute spinal cord injury: a prospective cohort study. Thromb Haemost 109:34-38, 2013

14. Glotzbecker MP, Bono CM, Wood KB, Harris MB: Postoperative spinal epidural hematoma: a systematic review. Spine (Phila Pa 1976) 35:E413-E420, 2010

15. Glotzbecker MP, Bono CM, Wood KB, Harris MB: Thromboembolic disease in spinal surgery: a systematic review. Spine (Phila Pa 1976) 34:291-303, 2009

16. Goldhaber SZ: Venous thromboembolism risk among hospitalized patients: magnitude of the risk is staggering. Am J Hematol 82:775-776, 2007

17. Guillamondegui OD, Gunter OL, Hines L, Martin BJ, Gibson W, Clarke PC, et al: Using the National Surgical Quality Improvement Program and the Tennessee Surgical Quality Collaborative to improve surgical outcomes. J Am Coll Surg 214:709-716, 2012

18. Hall BL, Hamilton BH, Richards K, Bilimoria KY, Cohen ME, Ko CY: Does surgical quality improve in the American College of Surgeons National Surgical Quality Improvement Program: an evaluation of all participating hospitals. Ann Surg 250:363-376, 2009

19. Hosmer DL, Lemeshow S: Applied Logistic Regression. New York: Wiley, 2000, Vol 2

20. Ingraham AM, Richards KE, Hall BL, Ko CY: Quality improvement in surgery: the American College of Surgeons National Surgical Quality Improvement Program approach. Adv Surg 44:251-267, 2010

21. Kasotakis G, Lakha A, Sarkar B, Kunitake H, Kissane-Lee $\mathrm{N}$, Dechert T, et al: Trainee participation is associated with adverse outcomes in emergency general surgery: an analysis of the National Surgical Quality Improvement Program database. Ann Surg 260:483-493, 2014

22. Khuri SF, Daley J, Henderson W, Hur K, Demakis J, Aust JB, et al: The Department of Veterans Affairs' NSQIP: the first national, validated, outcome-based, risk-adjusted, and peercontrolled program for the measurement and enhancement of the quality of surgical care. Ann Surg 228:491-507, 1998

23. Kimmell KT, Jahromi BS: Clinical factors associated with venous thromboembolism risk in patients undergoing craniotomy. J Neurosurg 122:1004-1011, 2015

24. Lee MJ, Konodi MA, Cizik AM, Weinreich MA, Bransford RJ, Bellabarba C, et al: Risk factors for medical complication after cervical spine surgery: a multivariate analysis of 582 patients. Spine (Phila Pa 1976) 38:223-228, 2013

25. Leon L, Rodriguez H, Tawk RG, Ondra SL, Labropoulos N, Morasch MD: The prophylactic use of inferior vena cava filters in patients undergoing high-risk spinal surgery. Ann Vasc Surg 19:442-447, 2005

26. Lim HY, Kishimoto M, Kitazono H, Ito H, Narita M, Gelber RP, et al: Risk factors for venous thromboembolism in Japan: a hospital-based case-control study. Hawaii Med J 66:236239, 2007

27. Merkow RP, Bilimoria KY, McCarter MD, Cohen ME, Barnett CC, Raval MV, et al: Post-discharge venous thromboembolism after cancer surgery: extending the case for extended prophylaxis. Ann Surg 254:131-137, 2011

28. Nicol M, Sun Y, Craig N, Wardlaw D: Incidence of thromboembolic complications in lumbar spinal surgery in 1,111 patients. Eur Spine J 18:1548-1552, 2009

29. Nieto JA, Bruscas MJ, Ruiz-Ribo D, Trujillo-Santos J, Valle R, Ruiz-Gimenez N, et al: Acute venous thromboembolism in patients with recent major bleeding. The influence of the 
site of bleeding and the time elapsed on outcome. J Thromb Haemost 4:2367-2372, 2006

30. Nieto JA, Camara T, Gonzalez-Higueras E, Ruiz-Gimenez N, Guijarro R, Marchena PJ, et al: Clinical outcome of patients with major bleeding after venous thromboembolism. Findings from the RIETE Registry. Thromb Haemost 100:789796, 2008

31. Oda T, Fuji T, Kato Y, Fujita S, Kanemitsu N: Deep venous thrombosis after posterior spinal surgery. Spine (Phila Pa 1976) 25:2962-2967, 2000

32. Pannucci CJ, Shanks A, Moote MJ, Bahl V, Cederna PS, Naughton NN, et al: Identifying patients at high risk for venous thromboembolism requiring treatment after outpatient surgery. Ann Surg 255:1093-1099, 2012

33. Patel AS, Bergman A, Moore BW, Haglund U: The economic burden of complications occurring in major surgical procedures: a systematic review. Appl Health Econ Health Policy 11:577-592, 2013

34. Ramanan B, Gupta PK, Sundaram A, Lynch TG, MacTaggart JN, Baxter BT, et al: In-hospital and postdischarge venous thromboembolism after vascular surgery. J Vasc Surg 57:1589-1596, 2013

35. Raslan AM, Fields JD, Bhardwaj A: Prophylaxis for venous thrombo-embolism in neurocritical care: a critical appraisal. Neurocrit Care 12:297-309, 2010

36. Sansone JM, del Rio AM, Anderson PA: The prevalence of and specific risk factors for venous thromboembolic disease following elective spine surgery. J Bone Joint Surg Am 92:304-313, 2010

37. Scarborough JE, Cox MW, Mureebe L, Pappas TN, Shortell CK: A novel scoring system for predicting postoperative venous thromboembolic complications in patients after open aortic surgery. J Am Coll Surg 214:620-628, 2012

38. Schairer WW, Pedtke AC, Hu SS: Venous thromboembolism after spine surgery. Spine (Phila Pa 1976) [epub ahead of print], 2014

39. Schoenfeld AJ, Herzog JP, Dunn JC, Bader JO, Belmont PJ Jr: Patient-based and surgical characteristics associated with the acute development of deep venous thrombosis and pulmonary embolism after spine surgery. Spine (Phila Pa 1976) 38:1892-1898, 2013

40. Steinberg SM, Popa MR, Michalek JA, Bethel MJ, Ellison EC: Comparison of risk adjustment methodologies in surgical quality improvement. Surgery 144:662-667, 2008

41. Takahashi H, Yokoyama Y, Iida Y, Terashima F, Hasegawa $\mathrm{K}$, Saito T, et al: Incidence of venous thromboembolism after spine surgery. J Orthop Sci 17:114-117, 2012
42. Tominaga H, Setoguchi T, Tanabe F, Kawamura I, Tsuneyoshi Y, Kawabata N, et al: Risk factors for venous thromboembolism after spine surgery. Medicine (Baltimore) 94:e466, 2015

43. Tran BH, Nguyen TJ, Hwang BH, Vidar EN, Davis GB, Chan LS, et al: Risk factors associated with venous thromboembolism in 49,028 mastectomy patients. Breast 22:444-448, 2013

44. Tyson MD, Castle EP, Humphreys MR, Andrews PE: Venous thromboembolism after urological surgery. J Urol 192:793797, 2014

45. Tzeng CW, Katz MH, Fleming JB, Pisters PW, Lee JE, Abdalla EK, et al: Risk of venous thromboembolism outweighs post-hepatectomy bleeding complications: analysis of 5651 National Surgical Quality Improvement Program patients. HPB (Oxford) 14:506-513, 2012

46. Whitmore RG, Stephen J, Stein SC, Campbell PG, Yadla S, Harrop JS, et al: Patient comorbidities and complications after spinal surgery: a societal-based cost analysis. Spine (Phila Pa 1976) 37:1065-1071, 2012

\section{Disclosures}

The authors report no conflict of interest concerning the materials or methods used in this study or the findings specified in this paper.

\section{Author Contributions}

Conception and design: Kimmell, Piper, Algattas. Acquisition of data: Piper, Algattas. Analysis and interpretation of data: Kimmell, Piper, Algattas, DeAndrea-Lazarus. Drafting the article: Piper. Critically revising the article: Kimmell, Piper, Algattas, Walter, Li, Silberstein, Vates. Reviewed submitted version of manuscript: all authors. Approved the final version of the manuscript on behalf of all authors: Kimmell. Statistical analysis: Piper. Administrative/technical/material support: Kimmell, Walter, Li, Silberstein, Vates. Study supervision: Kimmell, Piper, Vates.

\section{Correspondence}

Kristopher T. Kimmell, Department of Neurosurgery, University of Rochester Medical Center, 601 Elmwood Ave., Box 670, Rochester, NY 14642. email: kristopher_kimmell@urmc. rochester.edu. 